\title{
The Sales Lead Black Hole: On Sales Reps’ Follow-Up of Marketing Leads
}

\author{
Gaurav Sabnis \\ Sharmila C. Chatterjee \\ Rajdeep Grewal \\ Gary L. Lilien
}

July 2012

Gaurav Sabnis is Assistant Professor, Howe School of Technology Management, Stevens Institute of Technology (e-mail: sabnis@gmail.com). Sharmila C. Chatterjee is Senior Lecturer in Marketing, Sloan School of Management, Massachusetts Institute of Technology (e-mail: schatterjee@mit.edu). Rajdeep Grewal is Irving \& Irene Bard Professor of Marketing, Smeal College of Business, Pennsylvania State University (e-mail: rgrewal@psu.edu). Gary L. Lilien is Distinguished Research Professor of Management Science, Smeal College of Business, Pennsylvania State University (e-mail: glilien@psu.edu). The authors thank the Institute for the Study of Business Markets (ISBM) for the support provided for this research as well as Jane Lorimer of the Trade Show Bureau, James Haughey of Cahners Publishing, Ralph Richardson, and Jim Vick of Industrial Equipment News, and James McMenamin of Chilton Publishing for research sponsorship. The authors also thank Irwin Gross, Alok Kumar, Robert Meyer, William T. Ross Jr., David Schmittlein, Jagdip Singh, David Wilson, and especially the late Erin Anderson for support, comments, and feedback. 


\title{
The Sales Lead Black Hole: On Sales Reps' Follow-Up of Marketing Leads
}

\begin{abstract}
The sales lead "black hole" — the $70 \%$ of leads generated by marketing departments that sales representatives do not pursue-may result from competing demands on sales reps' time. Using the motivation-opportunity-ability framework, this study considers factors that influence sales reps' pursuit (or lack thereof) of marketing and self-generated leads. The proportion of time that sales reps devote to marketing leads depends on organizational lead prequalification and managerial tracking processes (extrinsic motivation), as well as marketing lead volume (opportunity), and sales rep experience and performance (ability). Consistent with a person-situation framework, individual sales rep factors also should moderate the influence of organizational processes on lead follow-up. Data from 461 sales reps employed by four firms confirm that as sales reps' experience increases, their responses to managerial tracking of lead follow-up and marketing lead volume decrease; responses to the quality of the lead prequalification process increase. As sales reps' performance improves, their response to the volume of marketing leads increases but their response to managerial tracking decreases. The interplay of individual sales reps' abilities and organizational marketing and sales processes explains differences in sales reps' follow-up of marketing leads.
\end{abstract}


In too many companies, Sales and Marketing feud like Capulets and Montagues.

—Kotler, Rackham, and Krishnaswamy (2006, p. 68)

On average, business-to-business (B2B) firms spend $65 \%$ of their marketing budgets on activities such as trade shows, product seminars, cold calling, database purchases, and telemarketing —all designed to yield information about prospective new customers (SiriusDecisions Inc. 2006). Yet studies show that sales representatives (reps) never contact approximately $70 \%$ of the leads generated by their marketing departments (Marcus 2002; Michiels 2009); instead, the leads disappear into a proverbial "sales lead black hole" (e.g., Hasselwander 2006). ${ }^{1}$ Kotler, Rackham, and Krishnaswamy (2006) suggest that one of the most contentious issues between sales and marketing functions is the lack of follow-up on leads that marketing generates (see also Churchill, Ford, and Walker 2003; Zoltners, Sinha, and Lorimer 2009). Sales reps complain about the poor quality of the leads; marketing complains about sales reps' poor follow-up (Biemans, Brencic, and Malshe 2010; Homburg and Jensen 2007; Homburg, Jensen, and Krohmer 2008). According to the executive director of the Sales Lead Management Association, poor follow-up "is not a small problem, it is a big problem, a 10 percent to 30 percent problem."’2 Despite widespread recognition (Smith, Gopalakrishna, and Chatterjee 2006; Watkins 2003), researchers have devoted little attention to either the causes or possible cures of this phenomenon (Chatterjee 1994; Jolson 1988). ${ }^{3}$

\footnotetext{
1 The number of marketing leads provided to sales reps can be so large that it is not possible for the sales reps to pursue all of them, even if they desired to do so; thus, the $70 \%$ figure reflects inadequacies of marketing as well as the sales function. [I removed the thank you here-I don't think this is such a big deal and we are over-thanking as it is] 2 The full text of the discussion about sales lead leakage at the Northern California Business Marketing Association on March 25, 2009, is available at http://blog.salesleadmgmtassn.com.

3 The considerable spending by B2B firms on lead generation activity makes it evident that they hope such leads get followed up, and the importance of this issue for B2B firms is well illustrated in observations by key industry figures. For example, Brian Carroll, CEO of In'Touch, asserts that "leads ignored by sales reps make up about 77\% of potential sales lost by the firm," and the Institute for the Study of Business Markets has held two recent conferences on ways to encourage marketing and sales to communicate better. These examples suggest that while practitioners are concerned about the issue we study here, the academic community has largely ignored it.
} 
Sales reps often argue that many marketing-generated leads (or marketing leads) lack the potential to result in actual sales, so they focus only on what they perceive to be "good leads" (Oliva 2006). However, Hasselwander (2006) asserts that firms often lose "ready-to-buy" customers that sales reps never contact, and Moreau (2006) reports that disagreements about classifying leads can cause sales reps to discard customers that would be highly likely to buy in the future. Both sides have support for their claims, but the overall result is a significant opportunity cost associated with poor lead follow-up, as well as demands for a viable solution to the sales lead black hole. Our research takes an initial step in this direction by investigating sales reps' decisions about how to allocate their time to marketing leads, which represents a trade-off with other uses of their time.

Sales reps allocate their time to customer acquisition (including lead follow-up), serving existing customers (e.g., retention, relationship management, upselling, cross-selling), and administrative or nonselling tasks. Customer acquisition time consists of the time reps spend following up marketing leads and time spent on leads that sales reps generate themselves from sources other than marketing, such as referrals from existing accounts. We refer to these latter opportunities as "self-generated leads," because sales reps generate them independently of marketing (Jolson 1988). Kotler, Rackham, and Krishnaswamy (2006, p. 76) note that "sales usually develops its own funnel, [which] form[s] an increasingly important backbone for sales management. Unfortunately, marketing often plays no role in these processes.”

Sales reps spend much of their time servicing existing customers and on administrative tasks such as paperwork, conference calls, and reviews. These activities constitute time that sales reps do not spend acquiring customers, and so we collectively refer to them as "non-acquisition" activities. Our hypotheses address sales reps' decision making about the allocation of proportions of total time among marketing leads, self-generated leads, and non-acquisition activities. (We develop a Dirichlet 
component regression model of their time allocation to account for the multivariate, proportional nature of our dependent variable).

We use the motivation-opportunity-ability (MOA) framework (e.g., MacInnis, Moorman, and Jaworski 1991) as a theoretical structure to identify organizational and individual (sales repspecific) factors that affect the allocation of time to marketing leads, self-generated leads, and nonacquisition activities. Firms can motivate sales reps to follow up on marketing leads by requiring marketing departments to prequalify leads and demanding that managers track the sales reps' pursuit of those leads. Firms also control the opportunity that sales reps have to follow up on marketing leads by providing more or fewer leads (i.e., lead volume). Finally, sales reps vary in their ability to close new leads (e.g., experience, or number of years spent in a sales job; past performance, or quota achievement in the previous year).

We test our hypotheses with data from 461 sales reps from four firms and use a regression model that account's for firm-specific effects. Our results show that as sales reps' experience increases, their responses to both managerial tracking of their lead follow-up activities and marketing lead volume decreases, but their response to the quality of the lead prequalification process increases. We also find that as sales rep past performance increases, their responses to marketing lead volume increases, but their response to managerial tracking decreases.

We proceed as follows: we next discuss the different demands on sales reps' time and use the MOA framework to develop hypotheses about which factors are likely to influence sales reps' time allocation processes. Then we describe the data, the Dirichlet component regression model for the sales reps' decision-making process, and the estimation procedure. Finally, we present our results and conclude with a discussion of the implications of our findings for both theory and practice. 


\section{CONCEPTUAL BACKGROUND}

\section{Time: Sales Reps' Most Precious Resource}

Sales reps' jobs entail three main responsibilities, as Figure 1 illustrates (e.g., Churchill, Ford, and Walker 2003; Weitz, Castlebury, and Tanner 2007): they undertake customer retention activities by managing ongoing relationships and growing revenues by upselling or cross-selling; they acquire new customers by pursuing marketing and self-generated leads; and they perform nonsales activities such as training and paperwork. Thus, sales reps must choose among several uses of time.

[Insert Figure 1 about here]

Through monitoring and compensation mechanisms, firms exert both direct (managerial tracking) and indirect (compensation schemes, lead prequalification) influences on sales reps' time allocation decisions. Researchers examining sales force effectiveness report that time allocation decisions have a significant impact on sales reps' performance (e.g., Deeter-Schmelz, Goebel, and Kennedy 2008; Leach, Liu, and Johnston 2005; Zoltners and Sinha 1980).

Our focus is on lead follow-up, which we define as customer acquisition efforts that rely on marketing and self-generated leads. Because of their other responsibilities, sales reps rarely have time to pursue all their leads. Consider two sales reps, Jason and Sally. Both spend 5\% of their time pursuing marketing leads, which might imply that their lead follow-up levels are the same. However, Jason spends $10 \%$ of his time on self-generated leads (i.e., a total of $15 \%$ of his time on customer acquisition), whereas Sally spends $25 \%$ of her time on self-generated leads (i.e., a total of $30 \%$ of her time on customer acquisition). Sally devotes twice as much of her time to customer acquisition as does Jason but a smaller proportion of her time to marketing leads. Thus, we conceptualize the proportion of time spent on marketing versus self-generated leads as time spent on customer acquisition. 
As our focus is on lead follow-up, we combine retention and nonsales activities and call them non-acquisition activities. We then structure the time allocation decision process faced by sales reps as the proportion of total time allocated among marketing leads, self-generated leads, and non-acquisition activities. Our goal is to identify and theorize about the factors that influence the proportion of time allocated to the follow-up of marketing leads; however we also empirically model how these factors influence the proportion of time allocated to the pursuit of self-generated leads. For self-generated leads we envision two potential processes: (1) a compensatory process, where if the proportion of the time allocated to marketing leads increases (decreases), the proportion of the time allocated to self-generated leads decreases (increases) and (2) independence between the proportion of the time allocated to marketing leads and self-generated leads. As we could find no research literature on self-generated leads and our focus is on marketing leads, our analysis of selfgenerated leads is exploratory.

\section{MOA Framework and Sales Rep Time Allocation}

Ideally, marketing generates high-quality leads, and sales reps follow up on most of them; however, the reality is quite different for several reasons, including differences in goals and time horizons. For example, marketing with its longer-term perspective likely considers leads that demand careful nurturing to be more attractive than sales does, because sales reps must focus on short-term quota attainment (Homburg and Jensen 2007). In addition, marketing may have a costeffective way to generate a large number of leads; a sales rep may simply want a few leads to help meet his or her quota. Thus, the leads that marketing views as most attractive may not meet the immediate needs of the sales rep.

Monitoring by sales managers could motivate sales reps to pursue those marketing leads. Sales managers might believe that a greater volume of marketing leads provides sales reps with a greater opportunity to achieve their goals. However, the degree of pursuit also depends on sales 
reps' individual circumstances (i.e., how did Sally get so many self-generated leads, which Jason lacked?). In other contexts, the MOA framework has proven useful in determining how such differences in circumstances might affect actions, such as customer information processing of advertisements (MacInnis, Moorman, and Jaworski 1991), knowledge sharing among employees (Siemsen, Roth, and Balasubramanian 2007), managerial assessments of marketing performance (Clark, Abela, and Ambler 2005), and new product introductions (Wu, Balasubramanian, and Mahajan 2004). In Figure 2, we identify the context-specific constructs we use to operationalize an MOA framework.

[Insert Figure 2 about here]

\section{Motivation}

Sales reps' motivation affects the way they pursue their goals. This motivation may be intrinsic (i.e., related to reps' individual performance and learning orientation, perceived effectiveness of individual efforts) or extrinsic (e.g., monetary incentives, processes implemented by the firm). Although a firm might manage intrinsic factors through its hiring practices (i.e., seeking employees with high intrinsic motivation), we focus on the extrinsic factors, those the firm can directly influence. Deci (1971) defines the motivation to work toward a specific external goal as extrinsic if that goal can be enhanced by feedback, rewards, and cues from the external environment. We focus on two features of the firm environment that can motivate sales reps: prequalification and managerial tracking.

Prequalification is a process by which the marketing department screens the leads it has generated and discards those it considers unattractive. Although lead generation (e.g., cold-calling, database purchases, telemarketing) often involves personnel outside the firm, lead prequalification is normally executed internally by marketing personnel. Sales reps cannot observe the objective quality of leads; they are motivated by their perceptions of lead quality or, more operationally, of the 
marketing department's lead qualification process. If sales reps' perception of the quality of the prequalification process is low, they likely focus more on their self-generated, familiar leads rather than on marketing leads. As reps' perceptions of the quality of the prequalification process increases, so should their expectations of success from pursuing these marketing leads. Sales reps prefer to avoid allocating time to leads that represent "casual inquirers," that is, customers that gather information simply to keep abreast of the latest offerings (Caravella 2006; Szymanski 1988). If sales reps have a favorable opinion of their firm's prequalification process, they will be confident that marketing has eliminated casual inquirers, that the leads they receive will be viable, and hence they will likely spend a greater proportion of their time on marketing leads.

$\mathrm{H}_{1 \mathrm{a}}$ : $\quad$ As the perceived quality of the prequalification process increases, the proportion of time spent on the follow-up of marketing leads also increases.

Another factor designed to motivate sales reps is managerial monitoring. Sales reps' compensation is usually tied closely to outcomes, such as sales quota achievement, but managerial monitoring also influences their behavior (e.g., Oliver and Anderson 1994). In the context of lead follow-up activities, managerial monitoring (or tracking) of whether sales reps pursue their marketing leads should act as an extrinsic motivator for sales reps. We define managerial tracking as the degree to which managers monitor sales reps' follow-up of marketing leads. Managerial tracking, a behavioral control, contrasts with sales reps' compensation based on quota achievement, which is an outcome measure. Thus the effect of managerial tracking on marketing lead follow-up should depend on how sales reps respond to behavioral controls. Firms that emphasize managerial tracking signal to sales reps that lead follow-up is important, which implies that follow-up of leads should increase.

$\mathrm{H}_{1 \mathrm{~b}}$ : As managerial tracking of marketing leads increases, the proportion of time spent on the follow-up of marketing leads increases.

\section{Opportunity}


If firms want sales reps to follow up on marketing leads, they must ensure that the reps have sufficient opportunity to do so (e.g., MacInnis, Moorman, and Jaworski 1991). The opportunity to pursue marketing leads should increase with the number of marketing leads received; therefore, we use marketing lead volume to measure the level of opportunity available. Therefore, we propose:

$\mathrm{H}_{2}$ : $\quad$ As marketing lead volume increases, the proportion of time spent on the follow-up of marketing leads increases.

\section{Ability}

In line with prior MOA research (e.g., Wu, Balasubramanian, and Mahajan 2004), we define ability as the set of skills and proficiencies needed to achieve a goal. If firms want sales reps to follow up on marketing leads, they must account for their relevant abilities, such as managing customer relationships and selling skills. We focus on two objective measures (sales rep experience and past performance) that extant research considers indicative of sales reps' abilities (e.g., Coughlan and Narasimhan 1992; Leong, Busch, and John 1989). ${ }^{4}$

As Szymanski and Churchill (1990) show, when sales reps gain experience, they become more efficient, and the number and strength of their customer relationships increase, as does their knowledge about the marketplace, all of which enhances their abilities to develop and sustain customer relationships. ${ }^{5}$ As sales reps' experience increases, they are better able to discern organizational signals, and their networks of lead-generating contacts (e.g., vendor reps, existing customers) grow richer. ${ }^{6}$ Thus, greater experience leads sales reps to focus more on existing

\footnotetext{
${ }^{4}$ Experience and past performance measure different aspects of sales rep ability. Experience indicates years spent in the job, resulting in detailed knowledge of the market, the selling process, and contacts with customers and vendors (Park and Holloway 2003). Past performance indicates an ability to achieve (and exceed) quotas through selling skills (Weitz 1978). Although both aspects of ability should benefit sales reps, their effect on time allocations need not be the same. Thus, we propose separate hypotheses for the effects of experience and past performance.

5 Although we expect sales rep experience to correlate with the sales rep's ability to build relationships with customers, there may be diminishing returns to increased ability. Thus, we estimated a model with a squared term for experience as an additional explanatory variable, but the coefficient for this squared term was not statistically significant.

${ }^{6}$ Although experience may not be the strongest indicator of sales reps' ability, it significantly affects their knowledge of the marketplace and ability to manage customer relationships, both of which influence lead follow-up activities (Coughlan and Narasimhan 1992; Szymanski and Churchill 1990).
} 
customers; the time they spend on acquisition adds to their increasingly rich sets of self-generated

leads (versus marketing leads, whose quality is unaffected by sales rep experience). We propose:

$\mathrm{H}_{3 \mathrm{a}}$ : As sales reps experience increases, the proportion of time spent on the follow-up of marketing leads decreases.

Sales reps who consistently exceed their quotas do so because of their relationships with customers and knowledge of the marketplace; they possess an ability to sell, identify customer needs, and communicate the value of the sales offerings (Leong, Busch, and John 1989; Sujan, Sujan, and Bettman 1988). Prior performance, in the form of past quota achievement, is also a significant indicator of sales reps' ability to manage customer relationships and perform the selling function, and it should influence lead follow-up activities. ${ }^{7}$ As reps' past performance improves, their ability to achieve their goals efficiently also improves, providing more time for activities other than pursuing marketing leads. ${ }^{8}$

$\mathrm{H}_{3 \mathrm{~b}}$ : $\quad$ As sales reps past performance increases, the proportion of time spent on the follow-up of marketing leads decreases.

\section{Moderating Hypotheses}

The time allocation process we have described requires sales reps to allocate their time among non-acquisition activities (the bulk of which is customer retention), marketing leads, and selfgenerated leads. With our focus on marketing leads, we also consider whether ability variables ${ }^{9}$ moderate the relationship between motivation/opportunity variables and the time allocated to

\footnotetext{
${ }^{7}$ Empirical research indicates that "sales reps are quota achievers rather than dollar maximizers" (Churchill, Ford, and Walker 2003, p. 232), and their prior quota achievements influence their lead follow-up behaviors (e.g., Gaba and Kalra 1999; Ross 1991). Sales reps with better previous sales performance are more likely to follow up on leads that offer a lower likelihood of closure but higher revenue potential, rather than the reverse (e.g., Mittal, Ross, and Tsiros 2002). ${ }^{8}$ Although sales reps may not allocate a fixed amount of time on lead follow-up, there are limits on the amount of time and tradeoffs have to be made; hence pursing one lead can make the next lead less attractive (see also Kotler, Rackham, and Krishnaswamy 2006).

${ }^{9}$ The interactions of ability with motivation and opportunity are most appropriate here: ability is individual-specific, whereas motivation and opportunity are firm-specific variables, consistent with the classical person-situation framework (Dickson 1982). We estimated a model with interactions between motivation and opportunity variables in a post hoc robustness assessment but found no empirical support for such relations.
} 
marketing leads. In Figure 3 we depict these moderating hypotheses, as well as the main effect hypotheses we have developed thus far.

[Insert Figure 3 about here]

\section{Motivation-Related Moderation Hypotheses}

Prequalification process and sales rep experience. Sales reps' perceptions of the quality of their firm's prequalification process (motivation) should have a positive relationship with time allocated to marketing leads $\left(\mathrm{H}_{1 a}\right)$. As sales reps' experience increases, their knowledge of the marketplace and the quality of their relationships with customers increases as well (e.g., Coughlan and Narasimhan 1992). Furthermore, an increase in sales reps' knowledge and relationship quality should enhance (1) the efficiency with which sales reps manage their existing clientele and (2) the ability of these sales reps to follow up on and close leads. Greater efficiency in managing existing relationships then should provide more time to pursue other activities, including existing customer management and potential new customer acquisition. ${ }^{10}$ Furthermore, a greater ability to close leads should motivate sales reps to pursue more leads. Because the prequalification process legitimizes leads, sales reps with greater experience should spend more time pursuing marketing leads that come from a more reliable lead generation process. We expect experience and the perceived quality of the prequalification to have a positive interaction effect on the proportion of time sales reps spend on marketing leads.

$\mathrm{H}_{4 \mathrm{a}}$ : The positive effect of the perceived quality of the marketing lead prequalification process on the proportion of time spent on the follow-up of marketing leads increases as sales rep experience increases.

Prequalification process and sales rep past performance. Leong, Busch, and John (1989) show that sales reps' past performance (quota achievement in previous year) relates positively

\footnotetext{
10 We can only speculate about what sales reps might do with time that becomes available due to their greater efficiency, but as the quality of the prequalification process increases, the option to pursue new customers seemingly should be more attractive and, in the aggregate, pursued to at least some extent.
} 
to reps' ability to identify customer needs and communicate the value of sales offerings. In a metaanalysis, Verbeke, Dietz, and Verwaal (2011) demonstrate that sales rep performance relates positively to selling-related knowledge, degree of adaptiveness, cognitive aptitude, and work engagement, but relates negatively to role ambiguity. Dubinsky and Hartley (1986) note that past performance relates positively to the likelihood that sales reps respond to motivational cues, including information about the quality of the organizational processes. Thus, an effective lead prequalification process should equip sales reps with reliable information that enables them to pursue the goal of acquiring new customers.

As sales reps' past performance improves, their ability to achieve their goal efficiently also improves. Thus, as past performance improves, sales reps should have more time to pursue sellingrelated activities, including the pursuit of new customers. Furthermore, as Mittal, Ross, and Tsiros (2002) find, an increase in past performance can enhance confidence about taking on the challenge of acquiring new customers. As past performance increases, sales reps can better discern organizational cues (Leong, Busch, and John 1989) and gain the ability to act on these cues (Verbeke, Dietz, and Verwaal 2011). As the quality of the lead prequalification process improves, sales reps also are likely to recognize better that lead follow-up is important from an organizational perspective, as well as possess the ability to exploit this recognition. Thus:

$\mathrm{H}_{4 \mathrm{~b}}$ : The positive effect of the perceived quality of the marketing lead prequalification process on the proportion of time spent on the follow-up of marketing leads increases as sales reps' past performance increases.

Managerial tracking and sales rep experience. Managerial tracking of marketing lead follow-up enables managers to track how well sales reps follow up on marketing leads. As the purpose of this process is to motivate sales reps to follow up (Kotler, Rackham, and Krishnaswamy 2006), managerial tracking should have a positive effect on the time that sales reps allocate to marketing leads $\left(\mathrm{H}_{1 \mathrm{~b}}\right)$. Lead prequalification and managerial tracking are structurally different, in that 
managerial tracking is a behavioral control mechanism (Anderson and Oliver 1987), whereas lead prequalification has nothing to do with sales reps' behaviors. The quality of the prequalification process provides motivational cues; managerial tracking directly motivates sales reps to behave in a certain manner.

Most sales compensation plans reward sales reps on the basis of the outcomes they achieve, rather than their behavior (e.g., Raju and Srinivasan 1996). The more experience sales reps have (i.e., more time in the job), the more time they have to learn that outcomes rather than behaviors matter. Thus, with greater experience, we expect a decrease in sales reps' responses to behavioral controls, such as managerial tracking (Coughlan and Narasimhan 1992). As more experienced sales reps likely believe they can meet quota targets in ways other than following up on marketing leads (e.g., selling to existing customers), their greater experience combined with managerial tracking should have a negative effect on the time they spend on marketing leads.

$\mathrm{H}_{5 \mathrm{a}}$ : The positive effect of managerial tracking of marketing leads on the proportion of time spent on the follow-up of marketing leads decreases as sales rep experience increases.

Managerial tracking and sales rep past performance. Sales reps with better past performance should be confident in their ability to acquire new customers (Mittal, Ross, and Tsiros 2002); however, as experience increases, sales reps' responsiveness to behavioral controls such as managerial tracking likely diminishes (e.g., Oliver and Anderson 1994). Unlike a lead prequalification process, which motivates sales reps by providing signals about organizational priorities, managerial tracking attempts to motivate sales reps by monitoring them, which works more poorly as sales reps' performance increases (Baldauf, Cravens, and Piercy 2001; Cravens et al. 1993). When sales reps' performance improves, increased managerial tracking should prompt heightened resistance. An increase in managerial tracking of lead follow-up, accompanied by an increase in sales reps' past performance, thus is likely to result in a decrease in the follow-up of marketing leads. 
$\mathrm{H}_{5 b}$ : The positive effect of managerial tracking of marketing leads on the proportion of time spent on the follow-up of marketing leads decreases as past performance increases.

Marketing lead volume and sales rep experience. As the volume of marketing leads increases, the opportunity to pursue and acquire new customers increases as well. Although this opportunity is identical for sales reps with different levels of experience, it is not clear that all reps take advantage of the opportunity similarly. When sales reps gain experience, their networks of leadgenerating contacts (e.g., vendor reps, existing customers) grow richer and increase the number of self-generated leads. Sales reps also should recognize the efforts needed to close their self-generated leads, which have known quality, unlike marketing leads of less certain quality. As marketing lead volume and sales rep experience increase, the total volume of leads (marketing and self-generated) also increases; in response, sales reps likely focus on leads with the greatest perceived potential, that is, decrease their emphasis on marketing leads.

$\mathrm{H}_{6 \mathrm{a}}$ : The positive effect of marketing lead volume on the proportion of time spent on the follow-up of marketing leads decreases as sales rep experience increases.

\section{Marketing lead volume and sales rep past performance. Sales reps' past performance} relates positively to their selling abilities (Leong, Busch, and John 1989), the likelihood that they respond to goal-oriented motivational cues (Dubinsky and Hartley 1986), and the time and ability they have to acquire new customers (Mittal, Ross, and Tsiros 2002). As their past performance increases, the time sales reps need to acquire customers should decrease. Combined with the positive relationship between sales reps' past performance and reps' inclination to respond to goaloriented cues, past performance thus should positively moderate the relationship between marketing lead volume and the proportion of time spent in pursuit of marketing leads.

$\mathrm{H}_{\mathrm{bb}}$ : The positive effect of marketing lead volume on the proportion of time spent on the follow-up of marketing leads increases as past performance increases.

\section{METHOD}




\section{Data Collection Procedure}

We mailed 2,666 surveys to sales reps from four B2B firms, three of which were members of Penn State's Institute for the Study of Business Markets. Each firm represented a different industry (scientific instruments, chemicals, copiers, and computers). Respondents reported (1) their past performance in terms of the percentage of their quota they achieved in the previous year; (2) their experience, measured in years spent working as a sales rep; ${ }^{11}(3)$ the total time in hours they worked each month; and (4) the time they spent in hours each month following up on marketing leads, following up on self-generated leads, or pursuing nonsales activities. (We assume any remaining time involves customer retention activities.)

The survey also included measures of sales reps' perceptions ("agree” to "disagree” on a 1-7 scale) of the quality of their firm's prequalification process (five items) and the extent of managerial tracking of marketing lead follow-up efforts (five items). We present these survey items in Appendix A. ${ }^{12}$ We received 562 surveys, for a response rate of $21.08 \%$. After screening for missing data related to our key constructs and an outlier analysis, we retained 500 usable responses.

The four firms were all B2B companies, and the customer accounts that their sales reps handled spanned a range of business sizes, from small to Fortune 100 corporations. The size of the sales forces varied from 55 (Firm 2, chemicals) to 2,500 (Firm 4, computers). The sales reps in our sample were customer-facing and handled mutually exclusive sets of customer accounts for their geographies. ${ }^{13}$ The compensation schemes in all four firms were based primarily on quota achievement, commissions, and bonuses for top-line sales. Although the compensation schemes

\footnotetext{
11 They also reported their experience in their current job, a variable highly correlated with overall experience.

${ }^{12}$ For the survey development, we conducted a pretest with 12 sales reps, who indicated, during personal debriefings, whether the questionnaire was easy to understand, unambiguous, and consistent in terms of interpretation. We framed the time allocation question as a monthly (as opposed to annual) measure, because the sales reps indicated that they generally considered this time frame.

${ }^{13}$ For large firms with multiple divisions and geographical locations, the definition of a "customer account" varies in terms of how it is allotted to sales reps. We defined customer accounts as entities assigned to customer-facing reps, on divisional and geographical bases.
} 
included bonuses tied to acquiring new customers, no component explicitly rewarded following up on marketing leads.

Our preliminary examination of the data showed that 39 respondents reported spending no time pursuing marketing leads. The t-tests for the differences between the explanatory variables for the zero and non-zero marketing lead follow-up time groups offered some support for our claims. For example, sales reps who spent no time pursuing marketing leads perceived the quality of lead prequalification (1.76) as significantly lower than those who pursued at least some marketing leads (2.21). In addition, 37 of the 39 respondents who indicated no marketing lead follow-up time came from one firm (computer industry), which suggests a potential for systematic bias. We removed the responses with no marketing lead follow-up time allocations from our analysis, leaving 461 surveys that reported on all relevant measures. ${ }^{14}$ In Table 1, Panel a, we present the descriptive statistics for the independent variables across the four firms; in Panel b, we present the descriptive statistics and correlation matrix for the entire sample.

[Insert Table 1 about here]

\section{Measure Validation and Common Method Bias}

Our dependent variable is the proportion of total time spent on marketing leads, selfgenerated leads, and non-acquisition. We collected the five-item motivation variable measures, managerial tracking, and perceived quality of prequalification on a 1-7 ("agree" to "disagree") scale. We used the number of leads that sales reps received from their marketing departments during the year as the opportunity measure of marketing lead volume. For the ability variables, we measured

\footnotetext{
14 To check for robustness, we included 112 surveys that left two or fewer explanatory variables blank and treated their missing values as random. The results were similar to our analysis of surveys that offered complete responses.
} 
sales rep experience as the self-reported number of years in a sales job ${ }^{15}$ and past performance as the percentage quota achieved the previous year.

As our measures for managerial tracking and quality of prequalification were perceptual, we conducted a confirmatory factor analysis (CFA) to determine the reliability and validity of the multiitem scales. The CFA model for the two continuous multi-item constructs exhibited good psychometric properties $\left(\chi_{19}^{2}=31.93\right.$, comparative fit index $=.99$, Tucker-Lewis index $=.99$, root mean square error of approximation $=.038$, standardized root mean square residual $=.037) .{ }^{16}$ To ensure that the scales measured the underlying constructs in each firm, we also conducted a multigroup CFA, which yielded fit indices that differed by less than $1 \%$ from the aggregate CFA.

We next assessed the scale reliabilities, all of which were greater than .80 (.89 for prequalification, .92 for managerial tracking); the average variance extracted for both constructs which exceeded .50 (.61 for prequalification, .58 for managerial tracking), in support of discriminant validity (Fornell and Larcker 1981) and protection against the adverse effects of multicollinearity in the presence of measurement error (Grewal, Cote, and Baumgartner 2004). Furthermore, the multicollinearity diagnostics for the explanatory variables showed that the condition indices were well below 30 (highest $=13.25)$, the variance inflation factors were lower than 10 (highest $=1.19$ ), and the variance proportions for all the variables on the dimensions with the highest condition indices were lower than .50. Multicollinearity thus did not pose a major concern.

To address common method bias concerns, we used different formats to collect the variables of interest and ensured temporal separation, with a time lag between the relevant questions in the survey instrument (Podsakoff et al. 2003). We measured the motivation variables using multiitem Likert scales; we measured opportunity and ability variables directly, using objective, self-

\footnotetext{
15 We also measured experience in the current job; the effect of current job experience was of the same sign and statistical significance as that of total sales experience.

${ }_{16}$ On the basis of the modification indices, we dropped one item for each construct.
} 
reported responses from sales reps. We achieved temporal separation by separating the criterion and predictor variables by at least 40 items in the survey instrument. To examine the possibility of common method bias, we used Harman's single-factor test. With an exploratory factor analysis, we also estimated a model that consisted of all predictor variables and both criterion variables. Five eigenvalues exceeded $1(>1.14)$, and a sixth equaled .97. Factor loadings on a single dimension showed that neither the criterion variables nor the objective measures loaded significantly on it. In the five-factor solution, the measures loaded separately along each of the five dimensions, closely aligned with our definition of the measures. Our findings were consistent with meta-analytic research (Doty and Glick 1998) and indicated that common method bias was not a serious issue.

\section{A Dirichlet Component Regression Model for Sales Reps' Time Allocation}

To model the effect of the MOA variables on the time allocated to marketing and selfgenerated lead follow-up, we used the framework in Figure 1 and theorized that sales reps could allocate each unit of time to one of three activities: marketing leads, self-generated leads, or nonacquisition activities. We view the sales rep decision process as a choice among the three activities for every time unit, based on the relative attractiveness of each option. This relative attractiveness depends on sales rep-specific and firm-level factors.

For sales rep $i$, let the non-zero attractiveness equal $A_{i m}$ for marketing leads, $A_{i s}$ for selfgenerated leads, and $A_{\text {in }}$ for non-acquisition activities. The probability that the sales rep allocates any given time unit to marketing leads then is $f\left(A_{i m} \mid A_{i s}, A_{i n}\right)$, to self-generated leads is $f\left(A_{i s} \mid A_{i m}, A_{\text {in }}\right.$ ), and to non-acquisition activities is $f\left(A_{i n} \mid A_{i s}, A_{i m}\right)$. As the number of time allocation decisions increases, the proportion of total time the sales rep allocates to the three tasks follows a Dirichlet distribution (e.g., Blackwell and MacQueen 1973): If a sales rep decides to allocate every hour of time as noted, the proportion of time allocated to the three tasks in a month is Dirichlet 
distributed. ${ }^{17}$ Thus, the sum-constrained proportions support the use of Dirichlet component regression (Gueorguieva, Rosenheck, and Zelterman 2008).

If the proportions of total time allocated to marketing leads and self-generated leads by a sales rep $i$ working in firm [i] are $Y_{i m}$ and $Y_{i s}$, respectively, and $Y_{i n}=1-Y_{i m}-Y_{i s}$ is the proportion of time allocated to non-acquisition, we can specify $Y_{i m}, Y_{i s}$, and $Y_{i n}$ as distributed Dirichlet, such that

$$
\left(Y_{i m}, Y_{i s}, Y_{i n}\right) \sim \operatorname{Dirichlet}\left(A_{i m}, A_{i s}, A_{i n}\right)
$$

where $A_{i m}, A_{i s}, A_{i n}$ are the positive real parameters of the distribution that represent the attractiveness of each option.

If $A_{i}=A_{i m}+A_{i s}+A_{i n}$, according to the properties of the Dirichlet distribution, the means for $Y_{i m}, Y_{i s}$, and $Y_{i n}$ are $A_{i m} / A_{i}, A_{i s} / A_{i}$, and $A_{i n} / A_{i}$, respectively, and the variances are $A_{i m}\left(A_{i}-A_{i m}\right) / A_{i}^{2}\left(A_{i}+1\right), A_{i s}\left(A_{i}-A_{i s}\right) / A_{i}^{2}\left(A_{i}+1\right)$, and $A_{i n}\left(A_{i}-A_{i n}\right) / A_{i}^{2}\left(A_{i}+1\right)$. The covariance terms $-A_{i m} A_{i s} / A_{i}^{2}\left(A_{i}+1\right),-A_{i s} A_{i n} / A_{i}^{2}\left(A_{i}+1\right)$, and $-A_{i m} A_{i n} / A_{i}^{2}\left(A_{i}+1\right)$ account for interdependence among the three time proportions (e.g., Evans, Hastings, and Peacock 2000, Chapter 10).

As is typical in Dirichlet regression models (e.g., Connor and Mosimann 1969; Hijazi and Jernigan 2009), the relationships between the explanatory variables and the proportions of time allocated to marketing and self-generated leads can be specified as follows:

$$
\begin{aligned}
& \log \left(A_{i m}\right)=\Omega_{\text {firm }[i]}+\left(\overline{\beta_{\text {firm }[i]}}\right)^{\prime}\left(\overline{X_{i}}\right), \text { and } \\
& \log \left(A_{i s}\right)=\Phi_{\text {firm }[i]}+\left(\overline{\gamma_{\text {firm }[i]}}\right)^{\prime}\left(\overline{X_{i}}\right),
\end{aligned}
$$

where $\Omega_{\text {firm }[i]}$ and $\Phi_{\text {firm }[i]}$ are firm-specific intercepts;

\footnotetext{
${ }_{17}$ Most firms, including those in our sample, evaluate and reward sales reps on a monthly basis.
} 
$\overline{\beta_{\text {firm }[i]}}$ and $\overline{\gamma_{\text {firm [i] }}}$ are firm-specific vectors of coefficients; and $\overline{X_{i}}$ is the vector of explanatory variables for sales rep $i$.

Because $Y_{i n}=1-Y_{i m}-Y_{i s}$, the Dirichlet parameter corresponding to non-acquisition for each sales rep $A_{i n}$ is defined as a sales rep-specific unknown constant (accounting for heterogeneity) for identification purposes, drawn from a vague prior uniform distribution $\mathrm{U}(0,100)$. We specify that the firm-specific intercepts $\Omega_{\text {frrm }[i]}$ and $\Phi_{\text {firm }[i]}$ each come from aggregate-level normal

distributions, whereas the firm-specific coefficients in the vectors $\overline{\beta_{\text {firm }[i]}}$ and $\overline{\gamma_{\text {firm[i] }}}$ are drawn from aggregate-level, multivariate normal distributions. With the $\overline{\beta_{\text {firm }[i]}}$ coefficients, we can test our hypotheses related to marketing lead follow-up; with the $\overline{\gamma_{\text {firm }[i]}}$ coefficients, we test hypotheses related to self-generated lead follow-up.

\section{Model Estimation}

We estimate the model using standard Markov Chain Monte Carlo procedures; we provide details about the prior specification, posterior distribution, and our sampling procedure in Appendix B. For the estimation, we used three concurrent chains (Bolstad 2007), such that for each chain, the first 5,000 iterations are the burn-in sample, and the next 50,000 iterations provide the sample for parameter estimation. To assess model convergence, we used the Gelman-Rubin statistics. To test for the statistical significance of the coefficients, we checked whether the $95 \%$ Bayesian posterior confidence intervals contained 0 (as recommended for Bayesian estimation; Rossi, Allenby, and McCulloch 2005). 


\section{RESULTS}

Our estimation reveals firm-level coefficients for the intercept term and all explanatory variables. As the significant firm-level coefficients are consistent with the aggregate-level coefficients (in the hierarchical Bayesian specification), we report only the aggregate-level coefficients in Table 2.

\section{[Insert Table 2 about here]}

Among the main effects, we find support for $\mathrm{H}_{1 \mathrm{a}}(\mathrm{b}=.64, p<.05)$, which suggests that as the perceived quality of prequalification increases, the proportion of time spent on marketing leads increases. We also find that as the perceived quality of prequalification increases, the proportion of time spent on self-generated leads decreases $(b=-.38, p<.05)$.

We had argued that managerial tracking of sales reps' follow-up of marketing leads would signal the importance that the managers place on lead follow-up and thus increase follow-up of marketing leads; however, our results show an opposite effect $\left(\mathrm{H}_{1 \mathrm{~b}}\right.$ : $\mathrm{b}=-.89, p<.05$; note that the effect of managerial tracking on self-generated leads is statistically non-significant: $\mathrm{b}=.28, n s)$. As discussed previously, as a behavioral control mechanism, managerial tracking may not be welcomed by "an excellent salesperson who refuses to accept behavior control" (Oliver and Anderson 1994, p. 63) and thus prompt reactance (Joshi 2010) from sales reps and a reduction in follow-up of marketing leads. Anderson and Oliver (1987) theorize that firms should benefit from behavior-based controls, but they find in practice (Oliver and Anderson 1994) that outcome-based controls are more effective for driving performance (confirmed by Heide 1994). With the result-driven nature of their jobs and achievement-based compensation schemes, sales reps likely are even more focused on outcomes than other employees. Thus managerial tracking is not just ineffective but even could lead to negative consequences relative to the intended objective of increasing marketing lead follow-up. 
We argued that as marketing lead volume increases, sales reps' opportunities to pursue marketing leads increases, which should increase follow-up of marketing leads; however, our results do not support this assertion $\left(\mathrm{H}_{2}: \mathrm{b}=.44, n s\right)$; also, marketing lead volume does not have a statistically significant effect on the follow-up of self-generated leads $(\mathrm{b}=.41, n s)$.

We find that sales reps' experience has no impact on follow up of marketing leads $\left(\mathrm{H}_{3 \mathrm{a}}: \mathrm{b}=\right.$ $-.19, n s)$ but does positively influence the follow-up of self-generated leads increases $(b=.24, p<$ .05). Finally, consistent with our expectations, as past performance increases, sales reps' follow up of marketing leads decreases $\left(\mathrm{H}_{3 \mathrm{~b}}: \mathrm{b}=-.31, p<.05\right)$; however, the follow-up of self-generated leads increases $(\mathrm{b}=.29, p<.05)$.

\section{Ability as a Moderator of the Effect of Motivation}

We find support for $\mathrm{H}_{4 \mathrm{a}}(\mathrm{b}=.71, p<.05)$, where we argued that experience enhances the positive effect of the perceived quality of prequalification on the proportion of time spent following up marketing leads. This finding extends work by Hunter and Perreault (2007), who find that sales reps consider information systems and processes useful only if they help those reps build and strengthen their relationships with customers and make sales. For self-generated leads we find that experience negatively moderates the negative effect of perceived prequalification quality on the proportion of time spent following up self-generated leads $(b=-.36, p<.05)$. However, the parameters for the interaction effect of past performance and prequalification on the proportion of time allocated to following up on marketing leads $\left(\mathrm{H}_{4 \mathrm{~b}}: \mathrm{b}=.04, n s\right)$ and self-generated leads $(\mathrm{b}=.09$, $n s)$ are not statistically significant.

In support of $\mathrm{H}_{5 a}$, the effect of managerial tracking on the follow-up of marketing leads decreases as sales reps' experience increases $(\mathrm{b}=-.55, p<.01)$. We also find that the positive effect of managerial tracking on the follow-up of self-generated leads decreases as sales reps' experience increases $(\mathrm{b}=-.44, p<.05)$. The results for marketing and self-generated leads suggest that sales 
reps' experience negatively moderates the effect of managerial tracking on the follow-up of both leads. Finally, we find support for $\mathrm{H}_{5 \mathrm{~b}}$ such that the positive effect of marketing lead volume on the follow-up of marketing leads decreases as sales reps' experience increases $(\mathrm{b}=-.21, p<.05)$; in contrast, the positive effect of marketing lead volume on the follow-up of self-generated leads increases with greater experience $(\mathrm{b}=.29, p<.05)$.

\section{Ability as a Moderator of the Effect of Opportunity}

In support of $\mathrm{H}_{6 a}$, experience negatively moderates the positive effect of marketing lead volume on the proportion of time spent on marketing leads $(b=-.11, p<.05)$. In contrast, we find that experience positively moderates the positive effect of marketing lead volume on the proportion of time spent on self-generated leads $(\mathrm{b}=.21, p<.10)$. In support of $\mathrm{H}_{6 \mathrm{~b}}$, the parameter for the interaction of past performance and marketing lead volume on the proportion of time spent on marketing leads is positive $(\mathrm{b}=.15, p<.05)$; this parameter for the proportion of time spent on selfgenerated lead is negative $(\mathrm{b}=-.19, p<.05)$.

\section{Robustness Checks}

The Bayesian shrinkage specification we use provides coefficients for all explanatory variables (including the intercept term) at the firm level. In terms of direction and statistical significance, these firm-level effects mimic aggregate effects (in the model specification, the firmlevel effects shrink to the aggregate effects). Therefore, the effects are consistent across the four firms from which we collected data. These four firms represent four different industries; this consistency in results suggests our findings are fairly robust.

We also estimated an alternative model that divided sales reps' time allocation process into two stages: (1) allocating time between customer acquisition and non-acquisition and (2) allocating customer acquisition time between marketing and self-generated leads. The results for the interaction hypotheses with this alternative model specification, in which marketing lead time 
proportion is the dependent variable ${ }^{18}$ are consistent with the results from the Dirichlet component regression model.

\section{Predictive Validity}

To validate the model, we followed the Bayesian approach used by Neelamegham and Chintagunta (1999). We randomly chose 150 observations to create a holdout sample, estimated the model using the remaining observations, and then arrived at an estimate of the dependent variables (i.e., proportion of time spent on follow-up of marketing and self-generated leads). We conducted this exercise five times and used root mean square errors (RMSE) to compare the hypothesized model (RMSE $=.072$ ) with several alternatives: (1) the Dirichlet component regression model with no explanatory variables $(\mathrm{RMSE}=.892),(2)$ a Dirichlet component regression model with only main effects $(\mathrm{RMSE}=.347)$, (3) a normal regression model with hypothesized effects (RMSE $=$ .423), (4) a Beta model for marketing lead time proportion and the rest of the time (RMSE $=.184$ ), and (5) a bivariate regression with marketing lead time and self-generated lead time as dependent variables $(\mathrm{RMSE}=.173)$. The RMSE for each alternative specification is considerably higher (i.e., poorer predictive fit) than for our model, in further support of our hypothesized Dirichlet component regression model.

\section{DISCUSSION}

Sales reps' follow-up of leads (both marketing and self-generated) is a crucial part of the customer acquisition process in B2B firms. We build on the MOA framework to suggest how firmlevel processes (lead prequalification, managerial tracking, and marketing lead volume) and sales reps' ability (experience and past performance) determine this follow-up of marketing and selfgenerated leads. The results from our analysis of data obtained from sales reps in four firms support our hypotheses; we now draw several theoretical and managerial implications.

\footnotetext{
${ }^{18}$ In the alternate specification, we used marketing and self-generated lead time allocations as proportions of customer acquisition time in stage 2, which summed to 1 and thus provided only one dependent variable in stage 2.
} 


\section{Theoretical Implications}

Our primary contribution is to provide insights on the follow-up of leads as a means to acquire customers in B2B firms - a critical domain in which B2B firms spend approximately $65 \%$ of their marketing budgets (SiriusDecisions Inc. 2006). By building our conceptual framework on the well-established MOA framework, we demonstrate its utility for the further study of the sales reps' pursuit of marketing leads. We also report results on the effect of MOA variables on the pursuit of self-generated leads; a focus that, to best of our knowledge, has received no scholarly scrutiny.

To implement the MOA framework in the context of lead follow-up by B2B firms, we identified critical sales rep-specific factors (ability) and organizational factors (motivation and opportunity). In turn, we built on the classic person-situation framework (Dickson 1982) to theorize that individual (ability) variables moderate the influence of organizational (motivation and opportunity) variables. We theorize and find evidence for critical interactions between motivation and opportunity with ability variables. For example, the interaction effect of experience and managerial tracking on marketing lead follow-up is negative; as experience increases, managerial tracking deters not only marketing but also self-generated lead follow-up. Thus, managerial tracking, when combined with greater sales rep experience, is likely to induce sales reps to respond by focusing attention away from customer acquisition in general and toward customer retention.

The interaction results also show that experience and past performance moderate the impact of firm-level factors on lead follow-up, underscoring the importance of considering heterogeneity in sales reps' abilities when studying the usefulness of behavior-based controls for various sales tasks. Behavior-based controls may motivate underperforming or inexperienced sales reps to engage in behaviors that the firm desires, but as sales reps' experience and past performance increases, these controls become counterproductive. The insights from our MOA framework suggest that contextdependent interactions should be considered further by any scholars who employ this framework. 
We contribute to prior literature by highlighting how perceptual measures of organizational processes can be used appropriately to capture the heterogeneity in their actual implementation and impact. For example, the measure of prequalification quality is not an objective, firm-level measure but rather is based on individual sales reps' perceptions. Considerable variance in these perceptions, coupled with the significant interaction effect with experience, suggest that research in sales force management should focus not only on the objective quality of sales-enabling processes but also on sales reps' perceptions of that quality.

We contribute to literature on sales reps' abilities (Szymanski 1988). Although experience and past performance are both indicators of sales reps' ability, we show that their effects differ and should be examined separately. With more experience, greater marketing lead volume exerts a negative effect on marketing lead follow-up; better past performance, instead, positively moderates the effect of marketing lead volume on marketing lead follow-up. These findings support efforts by previous researchers to differentiate among the different abilities of sales reps (e.g., Leong, Busch, and John 1989; Sujan, Sujan, and Bettman 1988).

\section{Managerial Implications}

Our study is useful for managers seeking to improve sales reps' follow-up on marketing leads. To illustrate the managerial value of our results and how they vary by firm, we calculate the elasticity of marketing lead follow-up time proportions with respect to the perceived quality of prequalification, level of managerial tracking, and marketing lead volume (Table 3).

[Insert Table 3 about here]

The elasticity of marketing lead follow-up time as a proportion of the perceived quality of the prequalification is 1.12 for the sample as a whole; a $1 \%$ increase in perceived prequalification quality produces a $1.12 \%$ increase in marketing lead follow-up time allocation. The elasticity is positive across all four firms but varies considerably (from .58 to 1.64). Even in our sample, we find 
a 3:1 ratio for the elasticity of the perceived prequalification quality for the least and most responsive firms. The low mean and high standard deviations ( $\mu=2.87$ on a $1-7$ scale, $\sigma=1.25$; Table 1 ) for perceptions of prequalification quality suggest considerable room for overall improvement in this key driver of marketing lead follow-up.

Because managerial tracking is primarily behavioral, with little bearing on sales reps' quotabased compensation and bonuses, the elasticity of marketing lead follow-up time allocations for managerial tracking is -.14 for the aggregate sample; thus managerial tracking is counterproductive, on average, for follow-up on marketing leads. However, this elasticity also varies across firms: It is negative for Firms 1 (scientific instruments) and 2 (chemicals) but positive for Firms 3 (copiers, where the elasticity is highest at .33) and 4 (computers). As we show in Table 1, Panel b, the average experience (8.83 years) in Firm 3 is the lowest among all firms (11.92 years overall); these less experienced sales reps may respond better to managerial tracking than their experienced counterparts in other firms.

The elasticity of lead follow-up time to the volume of leads is only -.07 on average across the four firms. The results pertaining to the volume of sales leads, though statistically significant, are thus of little managerial concern. Better prequalification and appropriate uses of managerial tracking are the areas where managers should focus their attention to fill their sales lead black hole.

\section{Limitations and Further Research}

Our study uses data from firms that are major players in their industries and have been so for several decades; they likely have sales processes and systems in place that incorporate their organizational learning about sales force management and lead generation. Consequently, our conclusions might not apply to smaller or younger firms whose sales processes are still evolving. The relationships we hypothesize also might vary in industries other than the four included in our study. 
Our study does not take into account heterogeneity in sales reps' stated customer acquisition responsibilities. Some may focus on maintaining relationships with existing key accounts while others may focus on acquiring new customers. The sales reps' job descriptions and stated responsibilities could provide alternative explanations for their allocations of time between marketing and self-generated leads.

We used perceptual measures for two explanatory variables: managerial tracking and quality of prequalification. Lead prequalification quality could vary across geographies and industrial sectors, depending on the expertise of the marketing personnel who conduct it. The extent of managerial tracking also could vary across managers, depending on their individual working style. Perceptual measures of managerial tracking and prequalification helped us capture within-firm heterogeneity, but they inherently suffer from measurement error and perhaps some psychological bias, which makes their use a limitation.

Our dependent variables indicate the proportions of time that sales reps allocate to two avenues for customer acquisition. Thus, the managerial implications we draw are limited to proportional allocations of time; they may not extend fully to related constructs such as actual time spent on marketing leads (in hours) or the number of leads followed. Similar analyses with other measures could add to and enrich our findings. Lead-level data from firms' customer relationship management systems might make such analyses possible.

\section{Conclusion}

For too long, sales and marketing have blamed each other for the sales lead black hole. There is more than enough blame to go around. We hope our results demonstrate that the solution requires not just more general cooperation but forms of cooperation that are tuned to individual sales reps' abilities and the firm's specific marketing and sales processes. 


\section{REFERENCES}

Anderson, Erin and Richard L. Oliver (1987), "Perspectives on Behavior-Based Versus OutcomeBased Salesforce Control Systems," Journal of Marketing, 51 (October), 76-88.

Baldauf, Artur, David W. Cravens, and Nigel F. Piercy (2001), "Examining the Consequences of Sales Management Control Strategies in European Field Sales Organizations," International Marketing Review, 18 (5), 474-508.

Biemans, Wim G., Maja Makovec Brencic, and Avinash Malshe (2010), “Marketing-Sales Interface Configurations in B2B Firms," Industrial Marketing Management, 39 (2), 183-94.

Blackwell, David and James B. MacQueen (1973), "Ferguson Distributions via Polya Urn Schemes," The Annals of Statistics, 1 (2), 353-355.

Bolstad, William M. (2007), Introduction to Bayesian Statistics, 2d ed. Hoboken, NJ: John Wiley \& Sons.

Caravella, Mary (2006), "Privacy, Strategic Information and New Customer Acquisition: Implications for Customer Relationship Management," doctoral dissertation, Harvard Business School.

Chatterjee, Sharmila C. (1994), "Salesperson Reaction to Management Lead Generation Programs: The Paradox Investigated," doctoral dissertation, The Wharton School, University of Pennsylvania.

Churchill, Gilbert A., Jr., Neil M. Ford, and Orville C. Walker Jr. (2003), Sales Force Management, 7th ed. New York: McGraw-Hill/Irving.

Clark, Bruce, Andrew Abela, and Tim Ambler (2005), “Organizational Motivation, Opportunity and Ability to Measure Marketing Performance," Journal of Strategic Marketing, 13 (December), 241-259.

Connor, Robert J. and James E. Mosimann (1969), “Concepts of Independence for Proportions with a Generalization of the Dirichlet Distribution," Journal of the American Statistical Association, 64 (1), 194-206. 
Coughlan, Anne T. and Chakravarthi Narasimhan (1992), “An Empirical Analysis of Sales-Force Compensation Systems," Journal of Business, 65 (1), 93-121.

Cravens, David W., Thomas N. Ingram, Raymond W. LaForge, and Clifford E. Young (1993), "Behavior-Based and Outcome-Based Salesforce Control Systems," Journal of Marketing, 57 (October), 47-59.

Deci, Edward L. (1971), "Effects of Externally Motivated Rewards on Intrinsic Motivation,” Journal of Personality and Social Psychology, 18, 105-115.

Deeter-Schmelz, Dawn R., Daniel J. Goebel, and Karen Kennedy (2008), "What Are the Characteristics of an Effective Sales Manager? An Exploratory Study Comparing Sales Rep and Sales Manager Perspectives," Journal of Personal Selling and Sales Management, 28 (1), 7-20.

Dickson, Peter R. (1982), "Person-Situation: Segmentation's Missing Link," Journal of Marketing, 46 (4), 56-64.

Doty, Harold D. and William H. Glick (1998), “Common Methods Bias: Does Common Methods Variance Really Bias Results?” Organizational Research Methods, 1 (January), 374-406.

Dubinsky, Alan J. and Steven W. Hartley (1986), “A Path-Analytic Study of a Model of Sales Rep Performance," Journal of Academy of Marketing Science, 14 (March), 36-46.

Evans, Merran, Nicholas Hastings, and Brain Peacock (2000), Statistical Distributions. New York: John Wiley \& Sons.

Fornell, Claes and David F. Larcker (1981), "Evaluating Structural Equation Models with Unobservable Variables and Measurement Error," Journal of Marketing Research, 18 (February), $39-50$.

Gaba, Anil and Ajay Kalra (1999), "Risk Behavior in Response to Quotas and Contests,” Marketing Science, 18(3), 417-434. 
Grewal, Rajdeep, Joseph A. Cote, and Hans Baumgartner (2004), "Multicollinearity and Measurement Error in Structural Equation Models: Implications for Theory Testing," Marketing Science, 23 (Fall), 519-529.

Gueorguieva, Ralitza, Robert Rosenheck, and Daniel Zelterman (2008), “Dirichlet Component

Regression and its Applications to Psychiatric Data," Computational Statistics \& Data Analysis, 52 (August), 5344-5355.

Hasselwander, Andy (2006), “B2B Pipeline Management” (accessed February 22, 2008), [available at http://b2bmarketingconfidential.blogspot.com/2006/11/b2b-pipeline-management.html]. Heide, Jan B. (1994), "Interorganizational Governance in Marketing Channels," Journal of Marketing, 58 (January), 71-85.

Hijazi, Rafiq H. and Robert W. Jernigan (2009), "Modeling Compositional Data Using Dirichlet Regression Models," Journal of Applied Probability \& Statistics, 4 (1), 77-91.

Homburg, Christian and Ove Jensen (2007), “The Thought Words of Marketing and Sales: Which Differences Make a Difference?” Journal of Marketing, 71 (July), 124-42

$\longrightarrow, \ldots$, and Harley Krohmer (2008), "Configurations of Marketing and Sales: A Taxonomy," Journal of Marketing, 72 (April), 133-54.

Hunter, Gary K. and William D. Perreault Jr. (2007), “Making Sales Technology Effective,” Journal of Marketing, 71 (January), 16-34.

Jolson, Marvin A., (1988), “On Qualifying Sales Leads: The Tight and Loose Approaches,” Industrial Marketing Management, 17, 189-196.

Joshi, Ashwin W. (2010), “Salesperson Influence on Product Development: Insights from a Study of Small Manufacturing Organizations," Journal of Marketing, 74 (January), 94-107.

Kotler, Philip, Neil Rackham, and Suj Krishnaswamy (2006), "Ending the War between Sales and Marketing," Harvard Business Review, 84 (July/August), 68-78. 
Leach, Mark P., Annie H. Liu, and Wesley J. Johnston (2005), “The Role of Self-Regulation Training in Developing the Motivation Management Capabilities of Salespeople," Journal of Personal Selling \& Sales Management, 25 (September), 269-281.

Leong, Siew Meng, Paul S. Busch, and Deborah Roedder John (1989), "Knowledge Bases and Sales Rep Effectiveness: A Script Theoretic Analysis,” Journal of Marketing Research, 26 (May), 164178.

MacInnis, Deborah J., Christine Moorman, and Bernard J. Jaworski (1991), “Enhancing and Measuring Consumers' Motivation, Opportunity, and Ability to Process Brand Information from Ads," Journal of Marketing, 55 (October), 32-53.

Marcus, Claudio (2002), “Re-Engineering Lead Management,” research report, Gartner Group (October 7).

Michiels, Ian (2009), “Lead Lifecycle Management: Building a Pipeline that Never Leaks,” research report, Aberdeen Group (July).

Mittal, Vikas, William T. Ross, and Michael Tsiros (2002), “The Role of Issue Valence and Issue Capability in Determining Effort Investment," Journal of Marketing Research, 39 (November), 455-468.

Moreau, Robert J. (2006), "Five Ways to Improve your Lead Management," (accessed January 24 2008), [available at http://www.marketingprofs.com].

Neelamegham, Ramya and Pradeep Chintagunta (1999), "A Bayesian Model to Forecast New Product Performance in Domestic and International Markets," Marketing Science, 18 (2) 115136.

Oliva, Ralph A. (2006), “The Three Key Linkages: Improving the Connections between Marketing and Sales," Journal of Business \& Industrial Marketing, 21 (6), 395-398. 
Oliver, Richard L. and Erin Anderson (1994), “An Empirical Test of the Consequences of Behaviorand Outcome-Based Sales Control Systems," Journal of Marketing, 58 (October), 53-67.

Park, Jeong-Eun, and Betsy B. Holloway (2003), “Adaptive Selling Behavior Revisited: An Empirical Examination of Learning Orientation, Sales Performance, and Job Satisfaction,” Journal of Personal Selling \& Sales Management, 23 (Summer), 239-251.

Podsakoff, Philip M., Scott B. MacKenzie, Jeong-Yeon Lee, and Nathan P. Podsakoff (2003), "Common Method Biases in Behavioral Research: A Critical Review of the Literature and Recommended Remedies," Journal of Applied Psychology, 88 (5), 879-903.

Raju, Jagmohan S. and V. Srinivasan (1994), “Quota-Based Compensation Plans for Multiterritory Heterogeneous Sales Forces," Management Science, 42 (10), 1454-1462.

Ross, William T., Jr. (1991), "Performance against Quota and the Call Selection Decision,” Journal of Marketing Research, 28 (August), 296-306.

Rossi, Peter E., Greg Allenby, and Rob McCulloch (2005), Bayesian Statistics and Marketing. Hoboken, NJ: John Wiley \& Sons.

Siemsen, Enno, Aleda V. Roth, and Sridhar Balasubramanian (2007), "How Motivation, Opportunity, and Ability Drive Knowledge Sharing: The Constraining-Factor Model,” Journal of Operations Management, 26 (May), 426-445

SiriusDecisions Inc. (2006), Marketing and Demand Creation in the B2B Marketplace: The Prospect's View, Alpharetta GA, Knowledgestorm [available at http://www.knowledgestorm.com/shared/write/collateral/CST/50513_84768_64432_Web cast.pdf].

Smith, Timothy M., Srinath Gopalakrishna, and Rabikar Chatterjee (2006), “A Three-Stage Model of Integrated Marketing Communications at the Marketing-Sales Interface," Journal of Marketing Research, 43 (November), 564-579. 
Sujan, Harish, Mita Sujan, and James Bettman (1988), "Knowledge Structure Differences Between More Effective and Less Effective Salespeople," Journal of Marketing Research, 25 (February), 81-86.

Szymanski, David M. (1988), "Determinants of Selling Effectiveness: The Importance of Declarative Knowledge to the Personal Selling Concept," Journal of Marketing, 52 (January), 64-77. and Gilbert A. Churchill Jr. (1990), “Client Evaluation Cues: A Comparison of Successful and Unsuccessful Salespeople," Journal of Marketing Research, 27 (May), 163-174.

Verbeke, Willem, Bart Dietz, and Ernst Verwaal (2011), "Drivers of Sales Performance: A Contemporary Meta-Analysis. Have Salespeople Become Knowledge Brokers?” Journal of the Academy of Marketing Science, 39 (3), 407-428.

Watkins, Harry (2003), Bridging the Great Divide: Process, Technology, and the Marketing/Sales Interface. Wellesley, MA: Aberdeen Group.

Weitz, Barton A. (1978), "Relationship between Salesperson Performance and Understanding of Customer Decision Making," Journal of Marketing Research, 15 (November), 501-516.

—, Stephen B. Castelbury, and John F. Tanner Jr. (2007) Selling Building Partnerships. New York: McGraw-Hill/Irwin.

Wu, Yuhong, Sridhar Balasubramanian, and Vijay Mahajan (2004), "When Is a Preannounced New Product Likely to Be Delayed?” Journal of Marketing, 68 (April), 101-113.

Zoltners, Andris A. and Prabhakant Sinha (1980), "Integer Programming Models of Sales Resource Allocation," Management Science, 26 (March), 242-260.

$\longrightarrow,-$, and Sally Lorimer, E (2009), Building a Winning Sales Force: Powerful Strategies for Driving High Performance. New York: American Management Association. 


\section{Appendix A}

\section{Survey Items Used to Measure Constructs}

\section{Independent Variables}

\section{Motivation}

Perceived Quality of Prequalification $(\alpha=.80)$

1. My company screens leads effectively.

2. My company does a terrible job of filtering out cold leads (reverse coded).

3. My company is competent at throwing out low return generating leads.

4. My company is very good at giving only hot leads to salespeople.

5. My company does a wonderful job of screening leads.

Managerial Tracking of Lead Follow-Up $(\alpha=.82)$

1. Call reports are used extensively by management to track the follow-up of company leads by salespeople.

2. My organization uses lead tracking software system to monitor follow-up of company leads by salespeople.

3. Tracking the follow-up of company leads by salespeople is not done formally in our organization (reverse coded).

4. My supervisor is very involved in monitoring the follow-up of company leads by salespeople.

5. Management emphasizes sales managers tracking the follow-up of company leads by their salespeople.

\section{Opportunity}

Marketing Lead Volume

1. About how many company leads do you get per year? 


\section{Ability}

Past Performance

1. Approximately what percentage of your sales quota did you obtain last year?

\section{Experience}

1. How many years of selling experience do you have in total?

\section{Dependent Variables}

1. About how many hours do you work on average per month? hrs/month

2. We count follow-up as starting when you contact a prospect in any way at all and ending when you know what the prospect will do (you get the order, somebody else gets the order, or you write them off as hopeless).

About how many hours typically per month do you spend following up on:

Company leads? hrs/month

Prospects you find yourself? hrs/month 


\section{Appendix B \\ Priors and Full Conditional Distributions}

In this appendix, we provide details on the priors and full conditional densities used in the Bayesian estimation of our Dirichlet regression model. Our dependent variables are the proportions of total time allocated to marketing leads and self-generated leads by sales rep $i$, or $Y_{i m}$ and $Y_{i s}$, respectively, and the proportion of time allocated to non-acquisition, $Y_{i n}=1-Y_{i m}-Y_{i s}$. We specify $Y_{i m}, Y_{i s}$, and $Y_{i n}$ as distributed Dirichlet, such that

$$
\left(Y_{i m}, Y_{i s}, Y_{i n}\right) \sim \operatorname{Dirichlet}\left(A_{i m}, A_{i s}, A_{i n}\right)
$$

where $A_{i m}, A_{i s}, A_{i n}$ are the positive real parameters of the distribution that represent the attractiveness of each option.

The relationships between the explanatory variables and the proportions of time allocated to marketing and self-generated leads can then be specified by:

$$
\begin{aligned}
& \log \left(A_{i m}\right)=\Omega_{\text {firm }[i]}+\left(\overline{\beta_{\text {firm }[i]}}\right)^{\prime}\left(\overline{X_{i}}\right), \text { and } \\
& \log \left(A_{i s}\right)=\Phi_{\text {firm }[i]}+\left(\overline{\gamma_{\text {firm }[i]}}\right)^{\prime}\left(\overline{X_{i}}\right),
\end{aligned}
$$

where $\Omega_{\text {firm[i] }}$ and $\Phi_{\text {firm[i] }}$ are firm-specific intercepts;

$\overline{\beta_{\text {firm }[i]}}$ and $\overline{\gamma_{\text {firm }[i]}}$ are firm-specific vectors of coefficients; and

$\overline{X_{i}}$ is the vector of explanatory variables for sales rep $i$.

The Dirichlet parameter $A_{\text {in }}$ is defined as a sales rep-specific unknown constant (accounting for heterogeneity) for identification purposes, drawn from a vague prior uniform distribution $\mathrm{U}(0,100)$.

\section{Likelihood Function}

The likelihood of observing the data, given unknown parameters, or the probability density

for $Y_{i m}, Y_{i s}$, and $Y_{i n}$, is given as: 


$$
p d f\left(\mathrm{Y}_{\mathrm{im}}, \mathrm{Y}_{\mathrm{is}}, \mathrm{Y}_{\mathrm{in}}\right)=\operatorname{pdf}\left(\mathrm{Y}_{\mathrm{im}}, \mathrm{Y}_{\mathrm{is}}, \mathrm{Y}_{\mathrm{in}} \mid \beta_{f i r m[i]}, \gamma_{f i r m[i]}\right) \varphi\left(\beta_{f i r m[i]}\right) \varphi\left(\gamma_{f i r m[i]}\right) .
$$

Following the properties of the Dirichlet distribution, the likelihood function of the unknown parameters, given the observed data, is of the following form:

$$
L\left(\beta_{f i r m[i]}, \gamma_{f i r m[i]} \mid Y_{i m}, Y_{i s}, Y_{i s}, X_{i}\right)=\prod_{i=1}^{N}\left[\frac{\Gamma\left(A_{i m}+A_{i s}+A_{i n}\right)}{\Gamma\left(A_{i m}\right) \Gamma\left(A_{i s}\right) \Gamma\left(A_{i n}\right)} Y_{i m}^{\left.{ }^{A_{i n}-1} Y_{i s}{ }^{A_{i s}-1} Y_{i n}^{{ }^{A_{i n}-1}}\right]} .\right.
$$

Because this likelihood function cannot be solved in closed form, and we model firm-specific heterogeneity, we use Markov chain Monte Carlo (MCMC) methods. We draw samples for the parameters from a Markov chain that was constructed using the full conditional densities. We then sample each of the full conditional densities using a Gibbs sampler (in case of a known distribution) or the Metropolis-Hastings (M-H) method if the full conditionals are not from a known family of distributions.

\section{Prior Distributions}

To estimate the model in Equations A1-A5) using MCMC methods, we place diffuse but appropriate prior distributions for all unknown parameters. For the coefficients related to marketing and self-generated lead time proportion, we specify parameters as firm specific $($ firm $[i]=1, . ., 4)$ with aggregate level multivariate normal distributions, that is, $\beta_{\text {frmm [i] }} \sim M V N\left(\beta_{m}, V_{m}\right)$ and $\gamma_{\text {frmm }[i]} \sim M V N\left(\gamma_{s}\right.$, $V_{s}$. We then specify the means of these aggregate mean parameters to have vague but common multivariate normal distributions, such that $\beta_{m} \sim M V N\left(\beta_{0}, V_{0 m}\right)$ and $\gamma_{s} \sim M V N\left(\gamma_{0}, V_{0 s}\right)$. The variance-covariance matrices for the parameters are specified as inverse Wishart distributions, or $\left(V_{m}\right)^{-1} \sim W i \operatorname{shart}\left(v_{m}, u_{m}\right),\left(V_{s}\right)^{-1} \sim W i \operatorname{ishart}\left(v_{s}, u_{s}\right),\left(V_{0 m}\right)^{-1} \sim W i \operatorname{shart}\left(v_{0 m}, u_{0 m}\right)$, and $\left(V_{0_{s}}\right)^{-1} \sim W i s h a r t\left(v_{0 s}, u_{0 s}\right)$. To reflect our lack of knowledge about the population means of the parameters, we specify $\beta_{0}=0$ and $\gamma_{0}=0$, and the variance-covariance matrices $u_{m}, u_{s}, u_{0 m}$, and $u_{0 s}$ as diagonal with large values (1000) for variances. The known dimensions of the Wishart distributions are specified by $v_{m}=11, v_{s}=11, v_{m}=$ 11 , and $v_{0 s}=11$, for the number of parameters. 
We specify the firm-specific intercepts as distributed normal with vague parameters, such that $\Omega_{\text {firm[i] }} \sim N\left(\mu_{\Omega}, \sigma_{\Omega}\right)$ and $\Phi_{\text {firm }[i]} \sim N\left(\mu_{\Phi}, \sigma_{\Phi}\right)$. The means $\mu_{\Omega}$ and $\mu_{\Phi}$ are distributed vague normal $N(0,1000)$. The inverse variance parameters $\left(\sigma_{\Omega}\right)^{-1}$ and $\left(\sigma_{\Phi}\right)^{-1}$ are distributed Gamma $(0.001,0.001)$.

\section{Full Conditional Distributions}

To construct the Markov chain by updating samples iteratively, we derived full conditional densities for all the parameters. First, the full conditional density of $\beta_{\text {frmm }[i]}$ does not have a known parametric distribution. The likelihood function of $\beta_{\text {firm[i] }}$ is:

$$
\begin{aligned}
& L\left(\beta_{\text {firm }[i]}\right) \propto \prod_{i=1}^{N}\left[\frac{\Gamma\left(\exp \left(\Omega_{\text {firm }[i]}+\beta_{\text {firm [i] }} X_{i}\right)+\exp \left(\Phi_{\text {firm }[i]}+\gamma_{\text {firm }[i]} X_{i}\right)+A_{\text {in }}\right)}{\Gamma\left(\exp \left(\Omega_{\text {firm }[i]}+\beta_{\text {firm }[i]} X_{i}\right)\right) \Gamma\left(\exp \left(\Phi_{\text {firm }[i]}+\gamma_{\text {firm }[i]} X_{i}\right)\right) \Gamma\left(A_{\text {in }}\right)} \times\right. \\
& \times \frac{1}{\left|V_{m}\right|^{1 / 2}} \exp \left((-1 / 2)\left(\beta_{\text {firm }[i]}-\beta_{m}\right)^{\prime}\left(V_{m}\right)^{-1}\left(\beta_{\text {firm[i] }}-\beta_{m}\right)\right)
\end{aligned}
$$

The prior is not conjugate with the likelihood, and the resultant conditional density does not have a known parametric distribution. Thus, we use a Metropolis-Hastings algorithm, with a multivariate normal distribution for the proposal density with previous draws of $\beta_{\text {firm }[i]}$ as the location parameters and the inverse Hessian of the log likelihood as the covariance matrix. We use a similar procedure for the full conditionals of $\gamma_{\text {frrm }[i]}$.

Second, the full conditional of aggregate parameters $\beta_{m}$ is multivariate normal, a known parametric distribution. Because the number of parameters is 11, and the number of firms in our data set is 4 , we sample $\beta_{m}$ using a Gibbs sampler from the conditional distribution:

$$
\beta_{m} \sim M V N_{11}\left(\left(4 V_{m}^{-1}+V_{0 m}^{-1}\right)^{-1}\left(V_{0 m}^{-1} \beta_{0}+\sum_{i=1}^{4} V_{m}^{-1} \beta_{f i r m[i]}\right),\left(4 V_{m}^{-1}+V_{0 m}^{-1}\right)^{-1}\right)
$$

We use a similar procedure to sample for the full conditionals of $\gamma_{s}$. 
Third, the full conditional of $\left(V_{m}\right)^{-1}$, which is the inverse variance-covariance of $\beta_{\text {frrm }[i]}$, is

Wishart, given by $\left(V_{m}\right)^{-1} \sim W\left(\left(v_{m}+4\right),\left(u_{m}^{-1}+\sum_{i=1}^{4}\left(\beta_{\text {firm }[i]}-\beta_{m}\right)\left(\beta_{\text {firm }[i]}-\beta_{m}\right)^{\prime}\right)\right)$, which is a known parametric distribution, so we can use a Gibbs sampler. We use a similar procedure to sample for the full conditional of $\left(\mathrm{V}_{\mathrm{s}}\right)^{-1}$. 
Figure 1

Demands on Sales Reps' Time

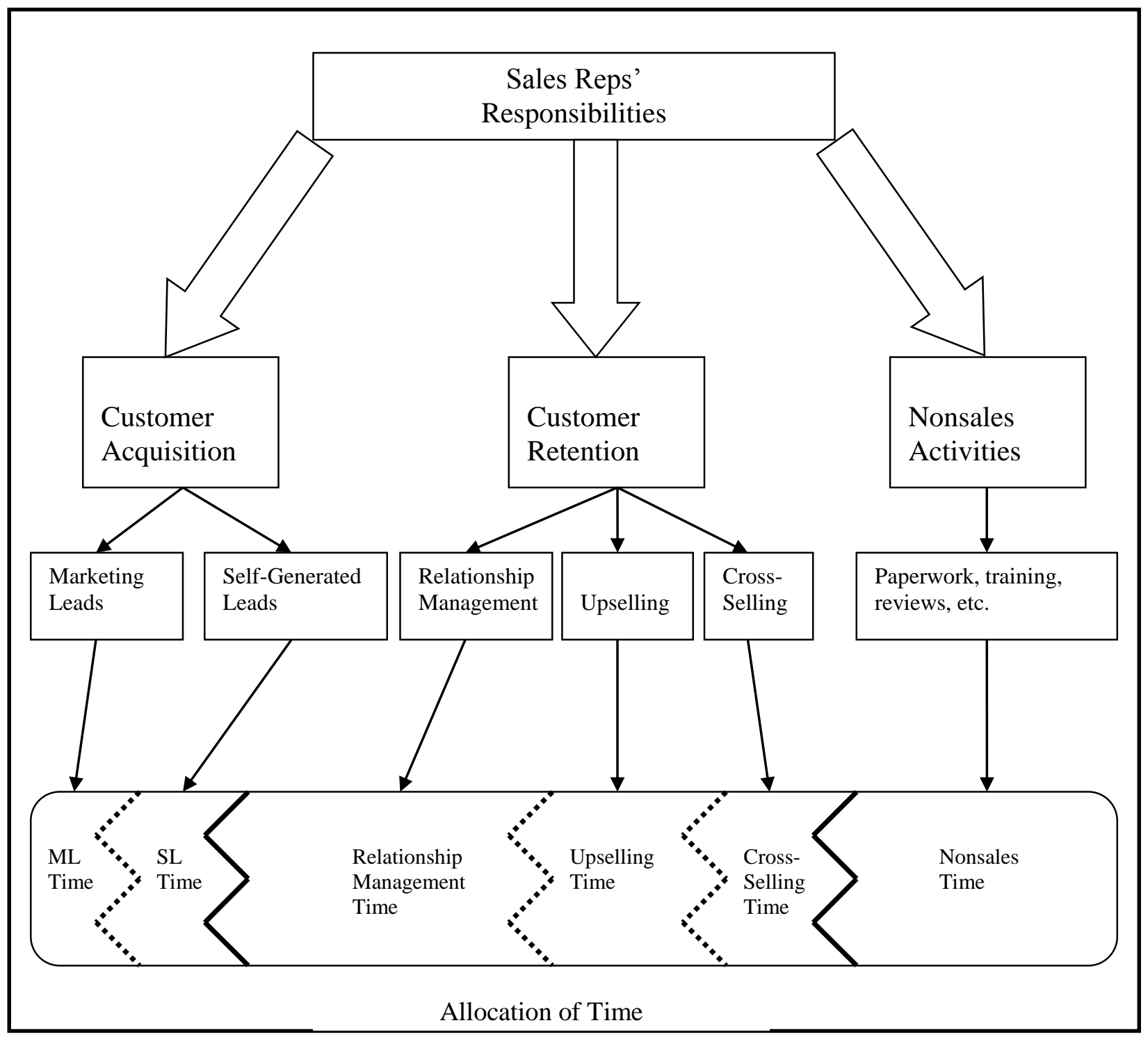


Figure 2

Motivation-Opportunity-Ability Framework for Customer Acquisition Time Allocation by Sales Reps

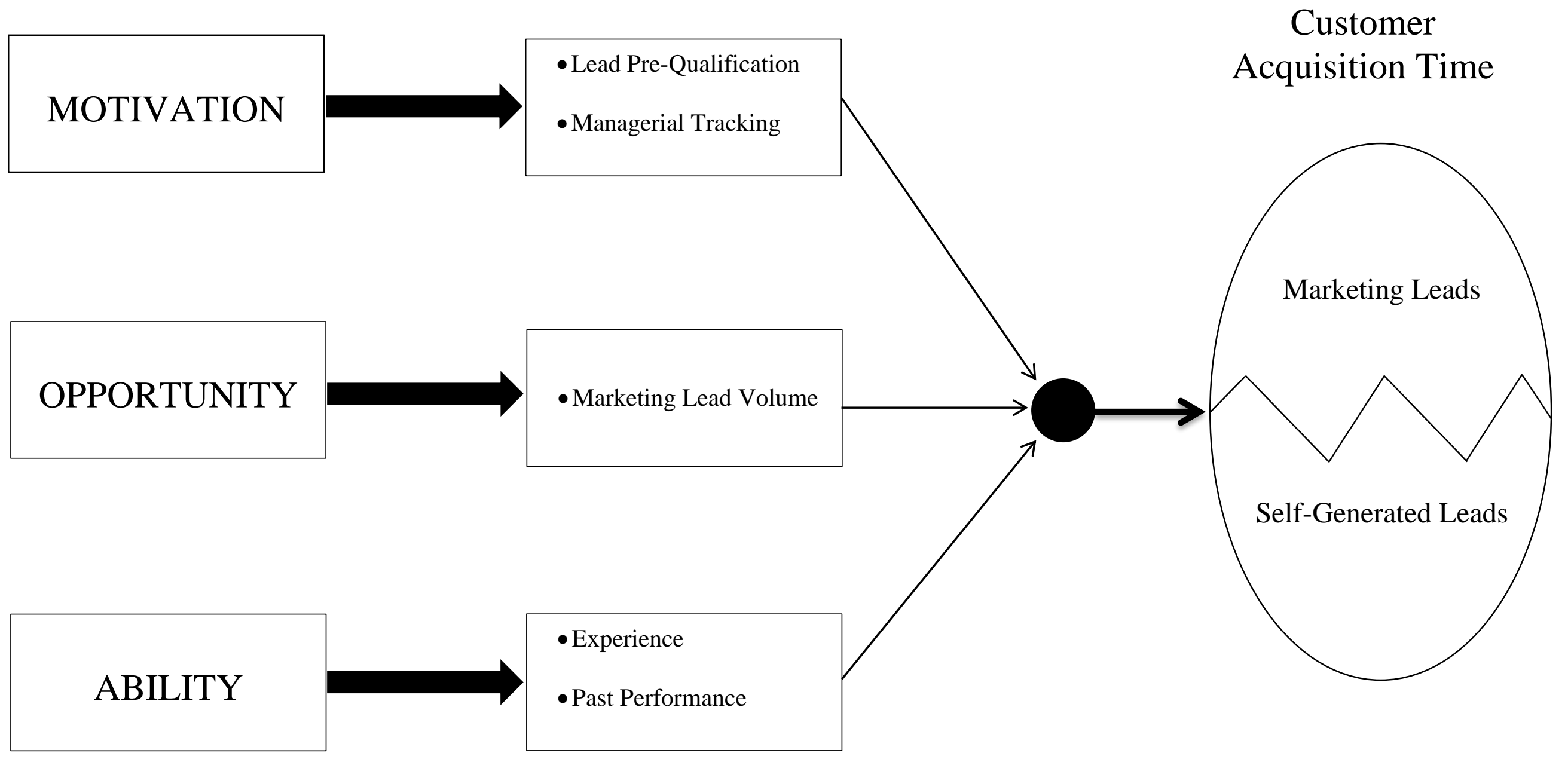


Figure 3

Research Hypotheses

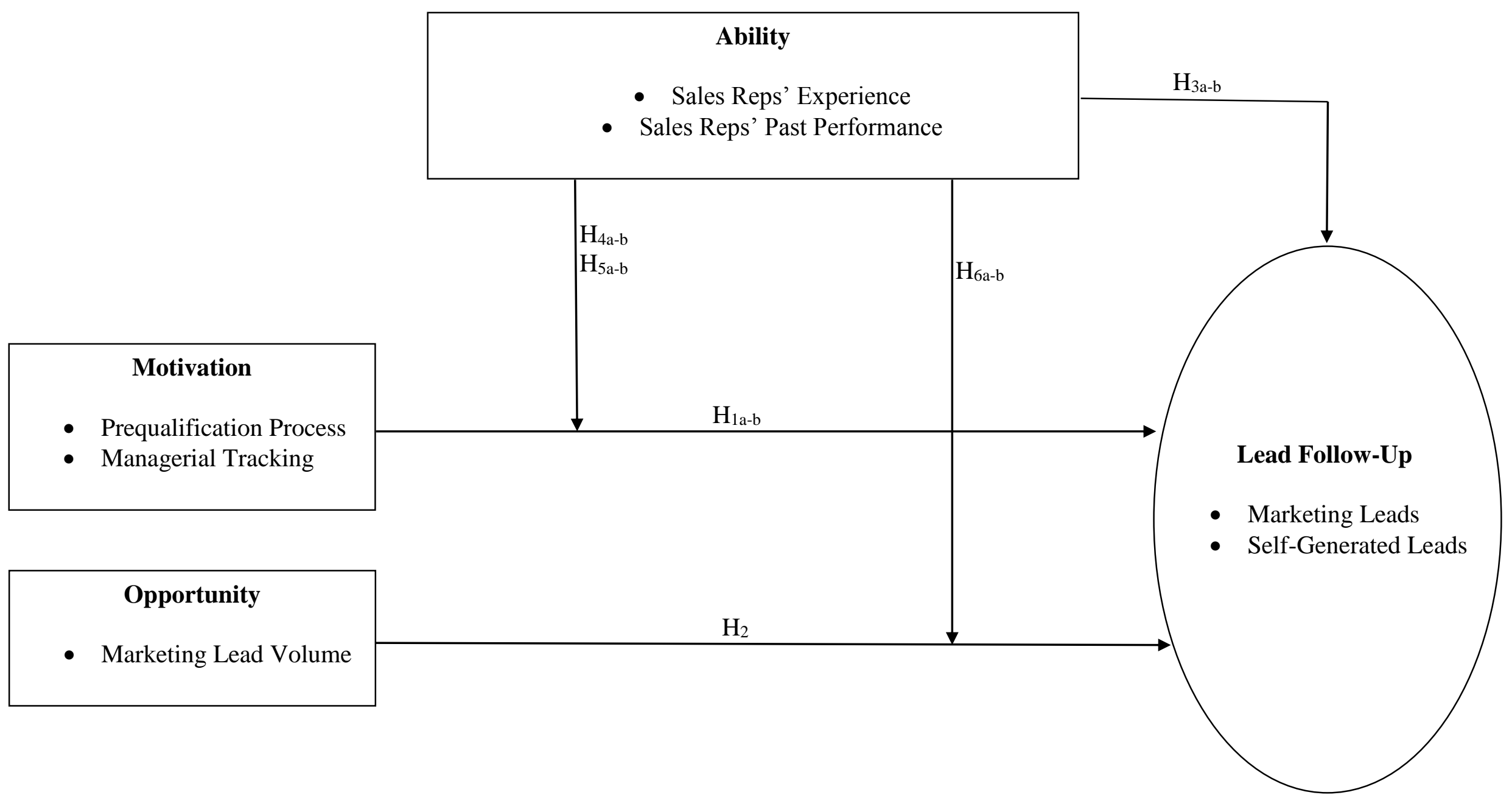


Table 1

Descriptive Statistics

(a) Firm-Specific Descriptive Statistics

\begin{tabular}{llccccc}
\hline \multirow{2}{*}{ Variable } & & Total & Firm 1 & Firm 2 & Firm 3 & Firm 4 \\
\hline Managerial tracking & $\mathbf{N}$ & 461 & 51 & 30 & 100 & 280 \\
\hline \multirow{2}{*}{ Quality of prequalification } & $\mathrm{M}$ & 2.81 & 3.62 & 2.39 & 3.20 & 2.55 \\
& $\mathrm{SD}$ & 1.33 & 1.16 & 1.16 & 1.33 & 1.28 \\
Marketing lead volume & $\mathrm{M}$ & 2.87 & 4.60 & 3.23 & 3.14 & 2.43 \\
& $\mathrm{SD}$ & 1.25 & 1.10 & 1.25 & .98 & 1.04 \\
Past performance & $\mathrm{M}$ & 48.61 & 109.30 & 199.48 & 18.42 & 32.14 \\
& $\mathrm{SD}$ & 141.52 & 111.1 & 428.5 & 21.68 & 88.57 \\
Experience & $\mathrm{M}$ & 111.64 & 97.37 & 99.53 & 104.31 & 118.17 \\
& $\mathrm{SD}$ & 50.37 & 22.32 & 15.53 & 52.73 & 54.47 \\
& $\mathrm{M}$ & 11.92 & 18.45 & 10.77 & 8.83 & 11.96 \\
& $\mathrm{SD}$ & 7.53 & 9.69 & 7.56 & 7.22 & 6.40 \\
\hline
\end{tabular}

(b) Bivariate Correlation Coefficients

\begin{tabular}{|c|c|c|c|c|c|c|c|c|c|}
\hline Variable & $\mathbf{M}$ & SD & MLT & SLT & MT & QP & MLV & NAQT & PP \\
\hline $\begin{array}{l}\text { Marketing lead follow-up time proportion } \\
\text { (MLT) }\end{array}$ & .057 & .091 & & & & & & & \\
\hline $\begin{array}{l}\text { Self-generated lead follow-up time } \\
\text { proportion (SLT) }\end{array}$ & .156 & .167 & $0.108^{* *}$ & & & & & & \\
\hline Managerial tracking (MT) & 2.81 & 1.33 & $0.189 *$ & -.041 & & & & & \\
\hline Quality of prequalification (QP) & 2.87 & 1.25 & $.246^{* *}$ & $-.011 *$ & $.38 * *$ & & & & \\
\hline Marketing lead volume (MLV) & 48.61 & 141.52 & -0.084 & -.001 & .05 & .06 & & & \\
\hline Non-acquisition time proportion (NAQT) & .788 & .196 & $-.548^{* *}$ & $-.891 * *$ & -.07 & -.05 & $-.07 *$ & & \\
\hline Past performance $(\mathrm{PP})$ & 111.64 & 50.37 & -.038 & $-.129 *$ & -.06 & $-.13 * *$ & -.05 & .05 & \\
\hline Experience (EXP) & 11.92 & 7.53 & $-.077 *$ & -.066 & .07 & $.13 * *$ & $.08^{* *}$ & $.05 * *$ & -.06 \\
\hline
\end{tabular}

* Correlation significant at the .10 level,

** Correlation significant at the .05 level.

Notes: Managerial tracking and quality of prequalification reflect the mean scores of four items (1-7 scale). Past performance is the percentage quota achieved in the previous year. Experience is the number of years that the respondent has worked as a sales rep. The sample size is 461 . The means (M) and standard deviations (SD) for the

independent variables apply across all four firms. 
Table 2

Results for the Dirichlet Component Regression Model

\begin{tabular}{llllll}
\hline & \multicolumn{3}{c}{ Marketing Lead Time } & \multicolumn{3}{c}{ Self-Generated Lead Time } \\
Proportion
\end{tabular}

$* p<.05$.

Table 3

Elasticity of Marketing Lead Time Proportion

\begin{tabular}{llllll}
\hline & & & & & \\
Controllable Factor & Aggregate & Firm 1 & Firm 2 & Firm 3 & Firm 4 \\
\hline Quality of prequalification & 1.12 & 1.24 & .58 & 1.64 & 1.43 \\
Managerial tracking & -.14 & -.08 & -.27 & .33 & .02 \\
Marketing lead volume & -.07 & .05 & -.14 & -.16 & .21 \\
\hline
\end{tabular}

Notes: Elasticities refer to the effect of controllable factors on marketing lead follow-up time, at the aggregate level and for each of the four firms. 